\section{The illness-disease dichotomy and the biological-clinical splitting of medicine}

\author{
Luigi Tesio (1) 1,2 Marco Buzzoni ${ }^{3}$
}

\begin{abstract}
In a recent paper, Sharpe and Greco (2019) argue that some clinical conditions, such as chronic fatigue syndrome (sometimes called myalgic encephalomyelitis), should be treated by altering the patient's experience and response to symptoms without necessarily searching for an underlying cause. As a result, we should allow for the existence of 'illnesses without (underlying) diseases'. Wilshire and Ward (2019) reply that this possibility requires unwarranted causal assumptions about the psychosocial origins of conditions not predicted by a disease model. In so doing, it is argued that Sharpe and Greco introduce epistemological and methodological problems with serious medical consequences, for example, patients feel guilt for seeking treatment for illnesses that only exist 'all in the mind', and medical researchers are discouraged from looking for more effective treatments of such conditions. We propose a view that integrates the insights of both papers. We abandon both the strict distinction between disease and illness and the naïve unidirectional account of causality that accompanies it. This, we claim, is a step towards overcoming the current harmful tendencies to conceptually separate (1) Symptom management and disease-modifying treatments. (2) Rehabilitative-palliative care and 'causal' curing. (3) Most importantly, biomedicine and clinical medicine, where the latter is currently at risk of losing its status as scientific.
\end{abstract}

\section{THE CONTROVERSY}

In a recent paper, Sharpe and Greco ${ }^{1}$ argue that some pathologies, such as chronic fatigue syndrome/myalgic encephalomyelitis, should be viewed as 'illnesses without disease'. For these, treatments should aim to alter the patient's experiences and his/her responses to their symptoms, even when an underlying cause cannot be identified. Sharpe and Greco recommend illness-focused (as opposed to

\footnotetext{
${ }^{1}$ Department of Biomedical Sciences for Health, Università degli Studi di Milano, Milano, Italy ${ }^{2}$ Department of Neurorehabilitation Sciences, Istituto Auxologico Italiano, IRCCS, Milano, Italy ${ }^{3}$ Dipartimento di Studi Umanistici, Università degli Studi di Macerata, Macerata, Italy
}

Correspondence to Prof. Luigi Tesio, Department of Neurorehabilitation Sciences, Istituto Auxologico Italiano, IRCCS, Milano 20122, Italy; luigi.tesio@unimi.it disease-focused) treatments, which could be psychological or behavioural, and which could improve the care of patients whose illnesses have not been associated with bodily disease. Patients with such conditions must fight against the prejudicial view-from which they must first free themselves-that their experience of illness should be regarded as 'not real' or as being 'all in the mind' simply because it is not associated with a bodily disease. ${ }^{2}$

In our opinion, Sharpe and Greco's concept of 'illness without disease' helps to clarify and promote the relative or, better, methodological autonomy and dignity of the clinical or psychosocial dimension of health and sickness, which recommends forms of treatment that may unjustly 'appear disappointingly insufficient at best and positively threatening at worst'.

In contrast to Sharpe and Greco, Wilshire and Ward ${ }^{4}$ claim that the notion of 'illness without disease' is methodologically problematic. They accuse Sharpe and Greco of using the distinction between illness and disease 'to identify a problem space that is not amenable to medical interventions at all, but rather must be addressed through social and/or psychologically based interventions'. ${ }^{5}$ Perhaps the most important point made by Wilshire and Ward is that Sharpe and Greco's concept of illness without disease 'can lead to unwarranted causal assumptions ${ }^{6}$ as it seems to assume that 'any experience not directly predicted by a disease model is necessarily of psychosocial origin'.

\section{REBALANCING THE EGG AND THE CHICKEN}

Although Wilshire and Ward's criticism of Sharpe and Greco glosses over several important distinctions, there is at least one sense in which they are correct: if we want to have an intersubjectively testable notion of health and sickness (where 'sickness' and 'health' are understood as antonyms), there must be some intersubjectively testable path leading from illness to the remaining causal network of all our experiences (including the aspects of reality perhaps 'abstracted' as a disease). In fact, 'unwarranted causal assumptions' would give up 'the principle of empiricism'-formulated by John S Mill and taken up, among others, by William James and Karl R Popper-according to which observation and experimentation are the only sources of evidence relevant for the acceptance or rejection of empirical statements. Moreover, in spite of Sharpe and Greco's fierce rejection of 'the dualist logic on which the illness/disease distinction is premised', 7 their concept of an 'illness without disease' mistakenly suggests entities that could exist independently from each other.

To be fair, Sharpe and Greco correctly reject a distinction 'between medically confirmed disease on the one hand and feelings/beliefs/attitudes on the other'. More precisely, they regard illness and disease 'in terms of different degrees and forms of abstraction from the totality of what is real' (p. 185, italics original). As they write, '[t]he experience of 'illness' [...] is a reality selected for perception by an organism as distinct from its normal existence in a negative way, and consequently demanding attention and rectification'. 8 They rightly reject that a patient's experience is not 'of the order of appearance rather than of ultimate reality" ${ }^{7}$ and, instead of thinking of illness and disease 'in terms of the hierarchical difference between subjective (or mental) and objective (or physical) realities', they 'propose that we could think of them in terms of different degrees and forms of abstraction from the totality of what is real'. ${ }^{8}$

However, while we accept that both the experience of illness and what is usually called disease are 'abstractions', this is not enough. It is still necessary to raise the question of the relationship both between such abstractions and between them and the rest of reality, clarifying how abstractions thus conceived are connected, at least in principle, in an intersubjectively reproducible and testable way. In other words, it seems to us that in Sharpe and Greco's argument there is a serious gap, and in order to fill it they ought to provide a clear view about the causal relationship that exists between the different results of our abstractions, and especially between, on the one hand, the experience of illness, and on the other, that aspect of reality which is usually referred to as 'disease', which always includes in some sense an organic correlate (and it goes without saying that if we do not wish to forsake science for magic and fiction, then this causal relationship should be such that, at least in principle, it can be made the object of an intersubjectively testable investigation). 
That said, however, we must add that Wilshire and Ward cannot accommodate one of the most important claims made by Sharpe and Greco, namely, that what is usually designated as the subjective, or better hermeneutic-normative, dimension of health is relatively autonomous. ${ }^{9}$ Experiences of illness are real as long as they are 'lived through'. In this sense, illness cannot be understood adequately only in terms, for example, of biological mechanisms. In fact, as we shall now briefly indicate, the general model defended by Wilshire and Ward seems to implicitly assume a one-sided conception of causality, ${ }^{10}$ that is, a unique direction of the causal vector, from organic reality to subjective lived experiences, excluding the possibility of the opposite flow. This in turn makes it difficult to understand the relationship between, for example, the doctor's necessarily typified and normalised concept of a disease and, on the other hand, the patient's unique personal experience of it.

Wilshire and Ward make a threefold distinction between (1) 'first-level models making specific claims about disease aetiology' supported by 'empirical evidence'. (2) 'second-level models', which 'do not identify the primary aetiology but do identify some of the proximal pathogenic mechanisms that underpin certain clinical phenomena' (ie, multiple sclerosis, Alzheimer's disease and many forms of cancer). (3) 'third-level models', or 'classificatory models', which 'do not identify aetiology or any specific pathogenesis but rather describe collections of clinical phenomena that often occur together, which may include self-reported complaints and objectively observable features. ${ }^{, 5}$

The third type of model is the most perplexing. It does not contain causal ascriptions, making it different from the other two kinds of model. This suggests that any purely subjective illness must be forever located in the third class as a collection of symptoms, as a merely provisional classification indexed to the current state of biomedical research, which, no doubt, will find, sooner or later, an underlying cause. Wilshire and Ward provide the historical example of the vague 'illness' whose symptoms included fatigue, weakness and muscle pain that was finally recognised by Brian McArdle as the muscle disease that now bears his name. This example is meant to suggest a methodological rule that devalues the causal role of symptoms in favour of more easily identifiable organic elements. However, symptoms should be so placed and understood within a causal network of connections to allow them to be considered just as real as their possible empirical-organic correlates, which is the most important point made by Sharpe and Greco, and a consequence of the principle of empiricism implicitly invoked by Wilshire and Ward themselves.

\section{HEALING THE DICHOTOMY: A BIDIRECTIONAL CAUSAL VECTOR BETWEEN ILLNESS AND DISEASE}

As far as this last point is concerned, it should be admitted that Wilshire and Ward's article provides a necessary first step in the direction of a more flexible, context-oriented or perspective-oriented conception of causality. They propose a distinction between levels that 'treats all types of causal claims in the same manner, whether they are phrased at a psychological or a biological level of description, and demands the same high standards of supporting evidence for both'. ${ }^{11}$ This distinction is important because it allows a psychological factor to be the cause of another psychological factor, rather than only speaking in terms of organic causes. However, this distinction is insufficient, because it keeps psychological and biological causes separate, precluding the possibility that the experience of illness may also have a 'downward' causal effect on its organic basis.

In our opinion, no direction of the causal vector should be privileged a priori. This is a compelling assumption if one adheres to what might be called a contextual and pragmatic theory of causality. According to this theory, what is or is not considered the cause of an event depends on the agent's adopted perspective, which is closely connected to his or her values and practical possibilities. In other words, cause and effect depend on the observer's theoretical or practical interests. Respecting John S Mill's lesson, not all of an event's infinite conditions are equally entitled to be regarded as its cause: we usually consider only one or some of its conditions as causes, namely those that are relevant to our purposes and which we believe we can, in principle, control via practical interventions. A specific cold is caused by a virus, and by factors such as the climate, the state of the patient's immune system, the patient's history and an environment that is not lethal for the virus. Of course, from a medical (clinical or epidemiological) perspective, potential causes are all factors of interest in prevention and/or therapy (in a broad sense including drugs, surgery, rehabilitation, hygienic precautions and education, routine check-ups, and programmes for population screening). ${ }^{12}$
If one adheres to such a contextual and pragmatic theory of causality, a 'downward' causation model can be as 'causal' as an 'upward' model. ${ }^{12}$ This position squares exactly with the well-known fact that 'subjective' states can influence biological features, and this influence could be more or less direct. In the more direct version, it could take the form of changed biological parameters. For instance, 'stress' (admittedly a form of 'illness') could cause detectable changes in blood steroid concentration and immunity markers (for a review, see Habib Yaribeygi et $\left.a^{13}\right)$. In other cases, the influence of 'illnesses without disease' on the purely biological aspect of sickness could be mediated by individual personality, behaviour and social context; for instance, depression appears to be a greater cause than it is an effect of adolescent obesity, a condition associated with a broad series of related diseases. ${ }^{14}$

Wilshire and Ward claim that, contrary to what Sharpe and Greco write, there is no evidence that patients reject behavioural treatments because they fear that their illness might be portrayed as 'not real' or being 'all in the mind'. Still, there is a preconceived attitude towards the direction of the causal vector contained in this claim, and indeed it appears to be false. For instance, only about $50 \%$ of people suffering from major depression also experience feelings of guilt. ${ }^{15}$ In addition, Wilshire and Ward neglect the opposite (and serious) risk that obsessive doctors (and patients) may shop around in search for latent diseases. More and more frequently, modern diagnostic technology and market pressure facilitate false-positive findings. ${ }^{16}$ This is particularly true if patients' illnesses are paired with observable dysfunctions such as (just focusing on neurological disorders) paralysis, dystonia and seizures, rather than symptoms such as headaches, fatigue, dizziness and tinnitus. ${ }^{17}$

Empirical research can indicate which organic factors should be considered the cause or effect of an illness in which a doctor plans to intervene. Identifying the chemical or electrophysiological correlates of a psychiatric 'disorder' can be of fundamental therapeutic importance, but the possibility that a cure might consist of words alone (which modify biological correlates) can never be excluded a priori.

On the basis of the above considerations, we claim that, in so far as Wilshire and Ward assume a single direction of the causal vector, from organic reality to subjective lived experience, and exclude the possibility of the opposite direction of 
influence, they cannot accommodate one of the most important demands of Sharpe and Greco, which, after reformulating, we intend to uphold in this paper as a demand for the recognition of the relative autonomy of the so-called hermeneuticnormative dimension of health and sickness. As already mentioned, strictly speaking, experiences of illness are real as long as they are 'lived through'. In this sense, illness cannot be entirely understood or explained in terms of the relatively fixed concepts, mechanisms and guidelines used in any particular scientific discipline, be it biology, psychology or any other. To fully understand an experience of illness, scientific disciplines are necessary but not sufficient. In medicine, methodological pluralism must be so radical that, first, all intradisciplinarily established causes should (in principle and in a somewhat widened context) be assumed to be capable of interacting with any other intradisciplinary cause, and second, any scientific concept or mechanism should (in principle) be assumed to be in an intersubjectively reproducible connection with the world of everyday life, where the singular patient and the clinical doctor ought always to have, so to speak, the last, difficult word in a science which is, ultimately for this reason, a 'human science ${ }^{18}$.

\section{HEALING THE DICHOTOMY: SYNDROMES AND DISEASES}

For similar reasons, diagnosis, mechanismpathogenesis and syndromes are not entirely separate entities, but levels on a gradient of knowledge, in the sense that, as with causes and effects, they are not written in stone. Is an Ebola virus infection the 'cause' of a patient's haemorrhages? The virus attacks the endothelial cells, but a cell is made of organs, cell organs are made of molecules, molecules are made of atoms, and atoms are made of subatomic constituents modelled in many ways. Any 'cause' could be considered a mechanism triggered by a deeper cause in an infinite regress. ${ }^{19}$

At the mechanism/syndrome interface, recognising a syndrome implies more than a simple association of observations. Which observations are sufficient to identify a syndrome? It is the prior hypothesis of a shared mechanism that makes some signs and symptoms appear related. The history of Cushing's syndrome is an example of this. ${ }^{20}$ Various symptoms of spontaneous excess cortisol secretion (ie, it is a syndrome resulting from corticoadrenal gland hyperfunction) could appear 'associated' (hence, syndromic) with visual field defects. ${ }^{21}$ However, this is only possible once it is understood that the same 'syndrome' can originate from a pituitary tumour in the brain (disease). At this point, a 'mechanism' 'seen' in a thought experiment and based on compression of the visual pathways can be postulated.

\section{HEALING THE DICHOTOMY: SYMPTOMATIC VERSUS DISEASE- MODIFYING TREATMENTS}

In medicine, the success of the illnessdisease dichotomy, which Sharpe and Greco strive to bridge, shares the same 'reductionist' origin with the simplistic distinction between 'symptomatic' and 'disease-modifying' approaches. Of course, 'symptomatic' treatments are those focused on problems downhill from the 'true cause' of the clinical condition. This distinction inspires everyday medical research language. For example, consider the case of multiple sclerosis, a chronic and disabling neural disease wherein 'symptomatic' approaches may include psychotherapy and motor rehabilitation, ${ }^{22}$ while 'disease-modifying' approaches may include immune 'modulating' drugs to marrow transplants. ${ }^{23}$ Paradoxically, this distinction shows the flexibility of the definition of 'cause', given that a 'diseasemodifying' treatment is not necessarily 'causal'. The dominant view ascribes the 'cause' to an autoimmune disorder, but the 'cause of the cause' remains unknown. The underlying assumption (neither justified nor justifiable) is that of an authentic core of reality hidden under superficial layers, which should be truly real. However, as argued above by Sharpe and Greco (and confirmed from the perspective of a pragmatic and contextual theory of causation), symptoms should be considered equally real as possible underlying 'causes'. The usefulness of reaching deeper causal layers is justified only insofar as it opens up a greater scope of possible interventions. Unfortunately, the implicit symptom-disease hierarchy may strongly bias research investment: why waste resources on 'symptoms' if we can search for a 'cause'? Further, it could delay useful hypotheses based on behavioural observations, consistent with a spiraliform rather than unidirectional process of knowledge advancement.

\section{HEALING THE DICHOTOMY: CAUSAL CURE VERSUS PALLIATIVE CARE}

The care/cure distinction itself, so neat in the English language, is a reflection of the illness/disease dichotomy. This divide is further exacerbated when the 'palliative' adjective is added. The term comes from the Latin word 'pallium' (mantle, veil), implying a derogatory connotation of hiding the real problem and settling for a superficial approach.

\section{HEALING THE DICHOTOMY: BIOMEDICINE VERSUS CLINICAL MEDICINE}

The authors of the two conflicting articles reviewed above strive to reconcile a dichotomy (Sharpe and Greco with a more decisive effort than Wilshire and Ward). They succeed only partially, and in different ways. Both assume that two sides of the same coin exist, or can at least be understood independently from one another. But there would be no coin if the two sides were split or any one of the sides erased. This metaphor equally applies to the dominant view of biomedicine as distinct from clinical medicine. Medicine as a whole is increasingly fragmented into two camps: biomedicine and clinical medicine (where the adjective comes from the Greek word 'clino', meaning bending or lying, of course, on the patient's bed). Biomedicine-supposed, so to speak, to be practised by 'the clever ones'-focuses on the cure of body parts, whereby a 'disease' can be more easily circumscribed. Clinical medicine, as practised by 'the good-hearted ones', focuses on caring for the 'illness' of the individual patient holistically, regardless of whether an underlying disease is observable: ${ }^{24}$ if medicine is the coin, nothing good can happen to it through this splitting process.

Consequently and unsurprisingly, clinical medicine is declining (a sad word play), in that it is losing its 'scientific' status. $^{24}$ The 'suffering of physicians', widely acknowledged in the literature, ${ }^{25}$ could result from this downgrading of clinical medicine to a 'soft-descriptiveapplicative' pseudoscience. An optimist might paint this downgrade as an upgrade to 'more than science' (ie, to a kind of art, ethics, philanthropy and ingeniousness). But this would still mark the expulsion of clinicians from the 'in' crowd. Psychiatry and physiatry (ie, Physical and Rehabilitation Medicine) seem to be the most strongly involved disciplines. These two specialties apparently share the absence of a target organ (although 'relational' organs have been claimed as intermediate targets of physiatry), ${ }^{26}$ and the property that they do not address 'diseases' in a strictly biological sense but 'whole person' disorders involving behaviour and perception. The target of psychiatry is mental 'disorders' ${ }^{27}$ while the ultimate target of 
physiatry is disability. In the original 1980 WHO's definition, ${ }^{28}$ the latter term indicated the restriction of 'activities' that can be performed only by a person as a whole (eg, locomotion and communication), while 'impairments' relate to body parts (eg, limb amputation and heart failure). From 2001, the WHO defined 'disability' as a broader 'umbrella term'; however, it retained 'activity limitations' at its core. ${ }^{29}$ For all person-oriented disciplines, the focus on the person, rather than body parts (no matter how tiny), entailed the cost of a lower scientific status from the perspective of lay people, medical students, ${ }^{30}$ healthcare professionals ${ }^{31}$ and scientometrics (a basis of research funding). ${ }^{32}$

\section{WHAT WE CAN DO: REFLECT ON LANGUAGE}

Besides the distinction between causal and palliative care, other linguistic tricks reveal attempts to deny full scientific dignity to the study of whole-person phenomena. We recall some of these below.

- The many 'conversion' disorders ${ }^{17}$ descend from the 'hysterical' disorders first recognised in the late 19th century by Charcot as distinct from malingering. ${ }^{33}$ The latest 2013 classification by the American Psychiatry Association proposed a definition of 'functional neurological symptom disorders'. The hope is that this new 'neurologicical' nomenclature 'leads to a significant modification in consideration of these symptoms from the clinicians' perspective'. ${ }^{34}$ Not surprisingly, neurologists are currently directing a growing stream of research towards 'the neurobiology' of functional (psychogenic) disorders; ${ }^{35}$ however, at the moment, these forms of 'illness without disease' (eg, chronic fatigue syndrome as per Sharpe's suggestion) can be treated with some success via combined behavioural approaches (ie, psychotherapy and motor rehabilitation). ${ }^{36,37}$

- Chronic fatigue syndrome is called myalgic encephalomyelitis by some, ${ }^{38}$ but the need for an 'encephalomyelitic' component of the syndrome (thus upgrading it to a disease) was never convincingly demonstrated.

- The prefix 'neuro' is now attached to different words outside medicine. Medical professionals, lay people and the media currently discuss neurorehabilitation, ${ }^{39}$ neurocognition and neuropsychology (also called 'scientific psychology ${ }^{40}$ ), and neuroethics ${ }^{41}$ and neuroeconomics. ${ }^{42}$ In brief, the illness-disease dichotomy and hierarchy are reflected in the reductionist biological drift now seen in 'human' sciences and not only in medicine. Sharpe and Greco's article focused on chronic fatigue syndrome but reopened a far more general Pandora's box.

The attempt of clinical medicine to preserve its identity is revealed by use of the '-iatry' suffix, jealously retained (for how long?) by a few specialties (ie, psychiatry, physiatry, paediatrics, geriatrics and phoniatrics). The suffix comes from the Greek lemma meaning 'curing', with no other specifications. This naming is at odds with most other non-surgical specialties, which are labelled using the '-logy' suffix (eg, neurology and cardiology) from the Greek lemma meaning language and understanding (as in intel $l i$ gence and logic). Needless to say, 'iatric' specialties are those drifting faster towards a lower 'scientific' status relative to other medical specialties. ${ }^{43}$

\section{WHAT WE CAN DO: EDUCATION AND RESEARCH}

An important academic effort is now underway to attenuate 'the long standing structural divide between the preclinical and clinical years in many medical curricula'. ${ }^{44}$ This proposed pedagogical shift requires a closer and more careful integration of the way that 'basic' and 'clinical' sciences are taught. ${ }^{45}$ It would re-interpret the linear 'bench to bedside' teaching approach inaugurated in Europe by Claude Bernard, the founder of experimental medicine, in the mid-19th century, ${ }^{46}$ and in USA by Abraham Flexner at the beginning of the 20th century. ${ }^{47}$ How to carry out this re-interpretation is still an open question. The dominance of the biomedical (ie, disease oriented) approach to medicine is further emphasised by the 'dual/combined' medical and engineering degree now offered by various universities in the USA (as examples, see columbia.edu, duke.edu and usf.edu) and elsewhere (for Italy, see hunimed.eu). This is a further sign that clinical medicine itself is considered too 'humanistic' to be a 'true' science. However, any solution that emphasises modularity (within the medical school, between the medical school and subsequent specialisations, and between medicine and engineering) runs the risk of being dichotomic and further downgrading medicine.

The climate of medical research must shift to enhance the prestige of clinical disciplines. Clinical research should avoid slavish adherence to biomedical paradigms and importing outcome variables, statistics and trial designs from their disdained Cinderella sisters (ie, the 'psycho-social' sciences). The traditional view of 'evidencebased medicine' places systematic reviews and randomised controlled trials on top of the evidence 'pyramid': an approach that risks obscuring sound evidence coming from other forms of studies. ${ }^{48}$ It should be acknowledged that finding evidence for the effectiveness of treatments using the methods of behavioural sciences is perhaps more difficult than doing the same in biological sciences, because of the many methodological peculiarities that go beyond the well-known difficulties of running double-blind, randomised controlled trials. ${ }^{43}$ However, this is merely an empirical matter. Behavioural medical specialisations, and even the various forms of 'alternative/complementary', 'holistic' medicine could adhere to the contemporary experimental paradigm, provided the proper methods are adopted; ${ }^{49}$ the crucial difference being that most 'complementary' medicines reject the experimental paradigm. $^{50}$

\section{TAKE HOME MESSAGE}

Gaining a deeper understanding of the difficulties that arise from upholding the abovementioned distinctions is a multifaceted task. Each of the conflicting articles discussed here provide an important contribution. A debate regarding the potential solutions goes far beyond the scope of the present article. However, we hope to have shown at least that a fair alliance of medicine and philosophy, not less than the alliance between biology and engineering, could certainly be helpful.

Contributors LT had the idea to realise this manuscript, given its relevance to the medical profession and education. Both authors provided equal contribution to the manuscript writing.

Funding The authors have not declared a specific grant for this research from any funding agency in the public, commercial or not-for-profit sectors.

Competing interests None declared.

Patient consent for publication Not required.

Provenance and peer review Not commissioned; externally peer reviewed.

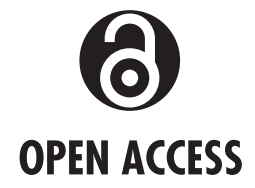

Open access This is an open access article distributed in accordance with the Creative Commons Attribution Non Commercial (CC BY-NC 4.0) license, which permits others to distribute, remix, adapt, build upon this work non-commercially, and license their derivative works on different terms, provided the 
original work is properly cited, appropriate credit is given, any changes made indicated, and the use is non-commercial. See: http://creativecommons.org/ licenses/by-nc/4.0/.

(C) Author(s) (or their employer(s)) 2020. Re-use permitted under CC BY-NC. No commercial re-use. See rights and permissions. Published by BMJ.

\section{Check for updates}

To cite Tesio L, Buzzoni M. Med Humanit Epub ahead of print: [please include Day Month Year]. doi:10.1136/ medhum-2020-011873

Accepted 22 May 2020

Med Humanit 2020;0:1-6. doi:10.1136 medhum-2020-011873

\section{ORCID iD}

Luigi Tesio http://orcid.org/0000-0003-0980-1587

\section{NOTES}

1. Michael Sharpe and Monica Greco (2019). "Chronic fatigue syndrome and an illness-focused approach to care: controversy, morality and paradox." Medical Humanities 45, no. 2: 183-87

2. Sharpe, Chronic fatigue syndrome:2

3. Sharpe: 186

4. Carolyn Wilshire and Tony Ward, 2019 "Conceptualising Illness and Disease : Reflections on Sharpe and Greco" Medical Humanities $0.01-5$ (published ahead of print).

5. Wilshire,"Conceptualising illness": 2

6. Wilshire:1

7. Sharpe: 184

8. Sharpe: 185

9. Marco Buzzoni (2003). "On Medicine as a Human Science." Theoretical Medicine and Bioethics, 24: 79-94.

10. Marco Buzzoni (2014)." The Agency Theory of Causality, Anthropomorphism, and Simultaneity", International Studies in the Philosophy of Science 28, no. 4: 375-95; Luigi Tesio (2014a). "Causing and being caused: items in a questionnaire may play a different role, depending on the complexity of the variable". Rasch Measurement Transactions, 28, no. 1:1454-55https://www.rasch.org/rmt/rmt281.pdf ; Luigi Tesio (2014b). "Items and variables, thinner and thicker variables: gradients, not dichotomies", Rasch Measurement Transactions 28 no. 3:1477-79 https:// www.rasch.org/rmt/rmt283.pdf.

11. Wilshire:4

12. Marta Bertolaso and Marco Buzzoni (2017). "Causality and levels of explanation in biology". In: Philosophical and scientific perspectives on downward causation, ed. by Michele Paolini Paoletti and Francesco Orilia (New York, NY: Routledge), pp. 164-79. Luigi Tesio and Stefano Scarano (2020). "Ground walking in chronic complete paraplegics:does epidural stimulation allow "awakening" of corticospinalcircuits? A wideranging epistemic criticism". American journal of physicalmedicine and rehabilitation, published ahead of print.

13. Habib Yaribeygi et al (2017). "The impact of stress on body function: a review'. EXCLI Journal, $16: 1057-72$.

14. Michelle L Byrne et al. (2015). "Adolescentonset depression: are obesity and inflammation developmental mechanisms or outcomes?". Child Psychiatry and Human Development, 46 no.6 : 839-50.

15. Erdem Pulcu et al (2013). "The role of self-blaming moral emotions in major depression and their impact on social-economical decision making". Frontiers in Psychology 4:310.
16. Gilbert Welch, Lisa M Schwarz, and Steven Woloshin (2012). "Overdiagnosed: Making People Sick in the Pursuit of Health". Boston, MA, USA: Beacon Press.

17. Mark J Edwards and Kailash P Bhatia (2012) "Functional (psychogenic) movement disorders: merging mind and brain'. The Lancet Neurology 11 no.3: 250-60

18. Marco Buzzoni. "On medicine as a human science." Theoretical Medicine 24 no.1: 79-94.

19. Christopher Craver and James Tabery (2019). "Mechanisms in Science". The Stanford Encyclopedia of Philosophy, https://plato.stanford.edu/archives/ sum2019/entries/science-mechanisms/; accessed Jan 31,2020

20. V C Medvei and Victor C Medvei (1991). "The history of Cushing's disease: a controversial tale". Journal of the Royal Society of Medicine 84 no.6: 363-66

21. R L Rovit et al. (1968). "Eye signs in patients with Cushing's syndrome and pituitary tumors". Archives of Ophthalmology 79 no.5: 512-22

22. Elizabeth Crabtree-Hartman (2018). "Advanced symptom management in multiple sclerosis". Neurologic Clinics, 36 no. 1: 197-218

23. Gavin Giovannoni (2018). "Disease-modifying treatments for early and advanced multiple sclerosis: a new treatment paradigm". Current Opinion in Neurology 31 no.3: 233-43.

24. Luigi Tesio (2010). "The good-hearted and the clever: clinical medicine at the bottom of the barrel of science' ". Journal of Medicine and the Person, 8 no.3: 103-11; Luigi Tesio (2015)." The clever and the good-hearted. Why clinical medicine can be a science" (in Italian). (Roma: II Pensiero Scientifico Editore).

25. Thomas R Cole and Nathan Carlin (2009).

"The suffering of physicians". The Lancet 374 no.9699:1414-15.

26. Luigi Tesio and Stefano Scarano (2020)." Physical and rehabilitation medicine has its target organs: the relational ones". International Journal of Rehabilitation Research,2020;43,3:193-194 https:doi.org/10.1097/ MRR.0000000000000404.

27. American Psychiatric Association (2013). "DSM-5 .Diagnostic and statistical manual of mental disorders": 5th Edition.

28. World Health Organization (1980)." International Classification of Functioning, Disabilities and Health" WHO, Geneva, Switzerland.

29. World Health Organisation (2001). "International Classification of Functioning, Disability and Health". WHO, Geneva, Switzerland.

30. Peter A Creed, Judy Searle, and Mary E Rogers (2010). "Medical specialty prestige and lifestyle preferences for medical students". Social Science and Medicine 71 no.6: 1084-88.

31. Dag Album and Steinar Westin (2008). "Do diseases have a prestige hierarchy? A survey among physicians and medical students". Social Science and Medicine 66 no.1: 182-88.

32. L Tesio et al. (1995). "Rehabilitation: The Cinderella of Neurological Research? A Bibliometric Study" ". Italian Journal of Neurological Sciences, 16 (1995), 473-77; Luigi Tesio(2010). "The good-hearted and the clever".

33. Christopher G Goetz (2016). "Chapter 2 - Charcot, Hysteria, and Simulated Disorders". In: Functional Neurologic Disorders, ed. by Mark Hallett, Jon Stone and Alan Carson, Handbook of Clinical Neurology (Elsevier), no. cxxxix: 11-23.

34. Benedetta Demartini, Armando D'Agostino, and Orsola Gambini (2016). "From conversion disorder (DSMIV-TR) to functional neurological symptom disorder (DSM-5): when a label changes the perspective for the neurologist, the psychiatrist and the patient". Journal of the Neurological Sciences 360:55-56

35. Mark J Edwards, Aikaterini Fotopoulou, and Isabel Pareés (2013). "Neurobiology of functional (psychogenic) movement disorders". Current Opinion in Neurology 26 no.4:442-47.

36. Glenn Nielsen et al., 2015. "Physiotherapy for functional motor disorders: a consensus recommendation". Journal of Neurology, Neurosurgery and Psychiatry 86 no. 10: 1113-19

37. Kathrin Czarnecki et al. (2012). "Parkinsonism and related disorders. Functional movement disorders: successful treatment with a physical therapy rehabilitation protocol". Parkinsonism and Related Disorders 18 no.3: 247-51.

38. Kjetil Gundro Brurberg et al. (2014). "Case definitions for chronic fatigue syndrome/myalgic encephalomyelitis (CFS/ME): a systematic review". BMJ Open 4 no.2.

39. Geoffrey A Donnan (2016). "NeuroRehabilitation". International Journal of Stroke 11 no.4: 385.

40. Patrick Haggard (2019). "The neurocognitive bases of human volition". Annual Review of Psychology 70 no.1: 9-28.

41. Thomasine Kushner and James Giordano (2017). "Neuroethics". Cambridge Quarterly of Healthcare Ethics 26 no.4: 524-25.

42. Pierre Livet (2010). "Rational choice, neuroeconomy and mixed emotions". Philosophical Transactions of the Royal Society B: Biological Sciences 365 no. 1538 :259-69.

43. Luigi Tesio (2019). "6.3B Scientific background of physical and rehabilitation medicine: specificity of a clinical science". The Journal of the International Society of Physical and Rehabilitation Medicine 2 no. $5: 113$.

44. Edward P Finnerty et al (2010). "Flexner revisited: the role and value of the basic sciences in medical education". Academic Medicine 85 no.2: 349-55

45. Anique B H De Bruin, Henk G Schmidt, and Remy M J P Rikers (2005). "The role of basic science knowledge and clinical knowledge in diagnostic reasoning: a structural equation modeling approach". Academic Medicine 80 no.8: 765-73.

46. Claude Bernard (1957). An Introduction to the Study of Experimental Medicine. Original edition in French. Birmingham, AL USA: Dover Publications, 1957.

47. Andrew H. Beck (2004). "The Flexner Report and the Standardization of American Medical Education". Journal of the American Medical Association 291 no.17: 2139-40.

48. Trisha Greenhalgh et al (2014)." Evidence based medicine: a movement in crisis?". BMJ Open 348:1-7; Stefano Negrini (2018). "Evidence in rehabilitation medicine". American Journal of Physical Medicine \& Rehabilitation 98 no.2: 88-96.

49. Jeffrey S Levin et al (2003). "Quantitative methods in research on complementary and alternative medicine". Medical Care 35 no.11: 1079-94.

50. Luigi Tesio (2013). "Alternative medicines: yes; alternatives to medicine: no". American Journal of Physical Medicine \& Rehabilitation 92 no.6:542-45.

\section{BIBLIOGRAPHY}

Album, Dag, and Steinar Westin. "Do diseases have a prestige hierarchy? A survey among physicians and medical students." Social Science \& Medicine 66, no. 1 (2008): 182-8.

American Psychiatric Association. DSM-5. Diagnostic and statistical manual of mental disorders, 5th ed. Washington DC USA: American Psychiatric Association Publishing, 2013. 
Bernard, Claude. "An introduction to the study of experimental medicine". Translated by Henry Copley Greene (original edition in French, 1865). Birmingham, AL USA: Dover Publications, 1957.

Bertolaso, Marta, and Marco Buzzoni. "Causality and levels of explanation in biology". New York, NY: Routledge, 2017.

Brurberg, Kjetil Gundro, Marita Sporstøl Fønhus, Lillebeth Larun, Signe Flottorp, and Kirsti Malterud. "Case definitions for chronic fatigue syndrome/myalgic encephalomyelitis (CFS/ME): a systematic review." BMJ Open 4, no. 2 (2014), e003973.

Buzzoni, Marco. "The agency theory of causality, Anthropomorphism, and Simultaneity." International Studies in the Philosophy of Science 28, no. 4 (2014): 375-95.

Byrne, Michelle L, Neil M O’Brien-Simpson, Sarah A Mitchell, and Nicholas B Allen. "AdolescentOnset depression: are obesity and inflammation developmental mechanisms or outcomes?" Child Psychiatry \& Human Development 46, no. 6 (2015): 839-50.

Cole, Thomas R, and Nathan Carlin. "The suffering of physicians." The Lancet 374, no. 9699 (2009): 1414-5.

Crabtree-Hartman, Elizabeth. "Advanced symptom management in multiple sclerosis." Neurologic Clinics 36, no. 1 (2018): 197-218.

Craver, Christopher, and James Tabery. "Mechanisms in science." The Stanford Encyclopedia of Philosophy (2019).

Creed, Peter A, Judy Searle, and Mary E Rogers. "Medical specialty prestige and lifestyle preferences for medical students." Social Science \& Medicine 71, no. 6 (2010): 1084-8.

Czarnecki, Kathrin, Jeffrey M Thompson, Richard Seime, Yonas E Geda, Joseph R Duffy, and J Eric Ahlskog. "Parkinsonism and related disorders functional movement disorders: successful treatment with a physical therapy rehabilitation protocol." Parkinsonism and Related Disorders 18, no. 3 (2012): 247-51.

Demartini, Benedetta, Armando D'Agostino, and Orsola Gambini. "From conversion disorder (DSM-IV-TR) to functional neurological symptom disorder (DSM5): when a label changes the perspective for the neurologist, the psychiatrist and the patient." Journal of the Neurological Sciences 360 (2016): 55-6.

Donnan, Geoffrey A. "Neurorehabilitation." International Journal of Stroke 11, no. 4 (2016): 385
Edwards, Mark J, Aikaterini Fotopoulou, and Isabel Pareés. "Neurobiology of functional (psychogenic) movement disorders." Current Opinion in Neurology 26, no. 4 (2013): 442-7.

Edwards, Mark J, and Kailash P Bhatia. "Functional (psychogenic) movement disorders: merging mind and brain." The Lancet Neurology 11, no. 3 (2012): 250-60.

Giovannoni, Gavin. “Disease-modifying treatments for early and advanced multiple sclerosis: a new treatment paradigm." Current opinion in neurology 31, no. 3 (2018): 233-43.

Goetz, Christopher G. " "Chapter 2 - Charcot, hysteria, and simulated disorders in functional neurologic disorders." In Handbook of Clinical Neurology, vol. 139, edited byMark Hallett, Jon Stone, and Alan Carson, 11-23: Elsevier, 2016.

Haggard, Patrick. "The neurocognitive bases of human volition." Annual Review of Psychology 70, no. 1 (2019): 9-28.

Kushner, Thomasine, and James Giordano. "Neuroethics." Cambridge Quarterly of Healthcare Ethics 26, no. 4 (2017): 524-6.

Levin, Jeffrey S, Thomas A. Glass, Lawrence H. Kushi, and John R. Schuck. "Lea Steele and Wayne B Jonas. "Quantitative methods in research on complementary and alternative medicine"." Medical care 35, no. 11 (2003): 1079-94.

Livet, Pierre. "Rational choice, neuroeconomy and mixed emotions." Philosophical Transactions of the Royal Society B: Biological Sciences 365, no. 1538 (2010): 259-69.

Medvei, V C, and Victor C Medvei. "The history of Cushing's disease: a controversial tale." Journal of the Royal Society of Medicine 84, no. 6 (1991): 363-6.

Nielsen, Glenn, Jon Stone, Audrey Matthews, Melanie Brown, Chris Sparkes, Ross Farmer, Lindsay Masterton., et al. "Physiotherapy for functional motor disorders: a consensus recommendation." Journal of Neurology, Neurosurgery \& Psychiatry 86, no. 10 (2015): 1113-9.

Rovit, R L, T D Duane, Richard L Rovit, and Thomas D Duane. "Eye signs in patients with Cushing's syndrome and pituitary tumors." Archives of Ophthalmology 79, no. 5 (1968): 512-22.

Sharpe, Michael, and Monica Greco. "Chronic fatigue syndrome and an illness-focused approach to care: controversy, morality and paradox." Medical Humanities 45, no. 2 (2019): 183-7.
. "Alternative medicines: Yes; alternatives to medicine: no." American journal of physical medicine \& rehabilitation 92, no. 6 (2013): 542-5.

. "Causing and being caused: items in a questionnaire may play a different role, depending on the complexity of the variable." Rasch Measurement Transactions 28 (2014a): 1454-5.

"Items and variables, thinner and thicker variables: gradients, not dichotomies"." Rasch Measurement Transactions 28, no. 3 (2014b) 1477-9.

. "The clever and the good-hearted. Why clinical medicine can be a science (in Italian). II Pensiero Scientifico Editore: Roma, 2015

"6.3B scientific background of physica and rehabilitation medicine: specificity of a clinical science." The Journal of the International Society of Physical and Rehabilitation Medicine 2, no. 5 (2019): 113-21.

Tesio, Luigi. "The good-hearted and the clever: clinical medicine at the bottom of the barrel of science." Journal of Medicine and the Person 8, no. 3 (2010): 103-11.

Tesio, L, C Gamba, A Capelli, F P Franchignoni, Chiara Gamba, and Andrea Capelli. "Rehabilitation: the Cinderella of neurological research? A bibliometric study." The Italian Journal of Neurologica/ Sciences 16 no. 7 (1995), no. : 473-7.

Tesio, Luigi, and Stefano Scarano. "Ground walking in chronic complete paraplegics: does epidural stimulation allow "awakening" of corticospinal circuits? A wide-ranging epistemic criticism." American Journal of Physical Medicine \& Rehabilitation (2020). [Epub ahead of print: $01 \mathrm{Jul} 2020$ ]

Welch, Gilbert., Lisa M Schwarz, and Steven Woloshin. "Overdiagnosed: Making People Sick in the Pursuit of Health". Boston, MA, US: Beacon Press, 2012

Wilshire, Carolyn, and Tony Ward. "Conceptualising illness and disease: reflections on Sharpe and Greco (2019)." Medical Humanities (2019): 1-5.

World Health Organisation. International classification of functioning, disability and health. Geneva: WHO, 2001. . International classification of impairments, disabilities, and handicaps. Geneva:WHO, 1980.

Yaribeygi, Habib, Yunes Panahi, Hedayat Sahraei, Thomas P Johnston, and Amirhossein Sahebkar. "The impact of stress on body function: a review." EXCLI journal 16 (2017): 1057-72. 